\section{Lymphocytic focus score as a prognostic tool}

We would like to thank Dr Arnaud et $a l^{1}$ for their comment on our article discussing the prognostic value of salivary gland assessments in primary Sjögren's syndrome (pSS). ${ }^{2}$

One of our findings was that having a lymphocytic focus score (LFS) $\geq 3$ (number of foci $/ 4 \mathrm{~mm}^{2}$ ) at the time of diagnosis contributes significantly to the risk of lymphoma development during pSS disease course. We agree that the follow-up time after biopsy is important to take into account because differences observed could merely be a result of the time that patients have been followed. As displayed in our article, we therefore analysed the incidence rate of non-Hodgkin's lymphoma (NHL) per 1000 person-years and showed that the incidence rate was higher for patients with an LFS $\geq 3$ than those with an LFS of either 1 or 2 (NHL incidence rate of 3.7 for LFS $=1,2.4$ for LFS $=2$ and 12.8 for LFS $\geq 3$, respectively, with a total of 1169 person-years at risk).

As suggested, we have additionally performed Kaplan-Meier survival analysis and Cox's proportional hazard regression analysis. The Kaplan-Meier curve showed reduced survival for the patient group with an LFS $\geq 3$ (Log-rank test: $p=0.009$ ). Using Cox's proportional hazard regression analysis, we observed that an LFS $\geq 3$ was significantly associated with the development of NHL both in a univariate analysis (HR 6.2; 95\% CI 1.3 to 29.3; $\mathrm{p}=0.021)$ and when adjusting for anti-SSA, anti-SSB, $\leq 40 \%$ immunoglobulin (Ig)A plasma cells and $\geq 25 \%$ IgM plasma cells in salivary gland specimens (HR 9.9; 95\% CI 1.2 to $82.4 ; \mathrm{p}=0.034)$.

In addition, in the original manuscript, we had performed multivariable linear regression analysis to assess the association between LFS $\geq 3$ and development of NHL. The results of multivariable logistic regression analysis, which is indeed more appropriate (variables in the equation: anti-SSA, anti-SSB, LFS $\geq 3, \leq 40 \%$ IgA plasma cells and $\geq 25 \%$ IgM plasma cells in salivary gland specimens), are comparative to our previously reported findings and show independent and significant prediction for lymphoma development of LFS $\geq 3$ (OR 14.72; 95\% CI 1.6 to $136.4 ; \mathrm{p}=0.018$ ).

Together, these results confirm our previous analyses that an LFS $\geq 3$ might help to identify pSS patients with an increased risk for development of NHL.

Anna P Risselada, ${ }^{1}$ Maria de Hair, ${ }^{2}$ Aike A Kruize, ${ }^{3}$ Johannes W J Bijlsma, ${ }^{4}$ Joel A G van Roon

'Department of Rheumatology, UMCU, Utrecht, The Netherlands

2Department of Clinical Immunology \& Rheumatology, Academic Medical Center/ University of Amsterdam, Amsterdam, The Netherlands

${ }^{3}$ Department of Rheumatology and Clinical Immunology, UMC Utrecht, Utrecht, The Netherlands

${ }^{4}$ Bijlsma Reumatologie, Utrecht, The Netherlands

${ }^{5}$ Department of Rheumatology \& Clinical Immunology/Lab Translational Immunology, UMC Utrecht, Utrecht, The Netherlands

Correspondence to Anna P Risselada, Department of Rheumatology, UMCU, Utrecht 3508 GA, The Netherlands; a.a.kruize@umcutrecht.nl

\section{Competing interests None.}

Provenance and peer review Not commissioned; externally peer reviewed.

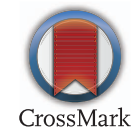

To cite Risselada AP, Hair M de, Kruize AA, et al. Ann Rheum Dis 2015;74:e31.

Received 15 December 2014

Accepted 16 December 2014

Published Online First 14 January 2015

Ann Rheum Dis 2015;74:e31. doi:10.1136/annrheumdis-2014-207150

\section{REFERENCES}

1 Arnaud L, Devilliers H, Amoura Z. Survival analysis versus event count. Ann Rheum Dis 2014;73:e37.

2 Risselada AP, Kruize AA, Goldschmeding R, et al. The prognostic value of routinely performed minor salivary gland assessments in primary Sjögren's syndrome. Ann Rheum Dis 2014;73:1537-40. 